\title{
Evaluation of Antibiotic Treatment on the Duration of Hospitalization of Patients with Erysipelas and Bacterial Cellulitis
}

\author{
Ewelina Kosior · Adam Reich (D)
}

Received: October 18, 2018 / Published online: December 7, 2018

(c) The Author(s) 2018

\section{ABSTRACT}

Introduction: Erysipelas and bacterial cellulitis are two of the most common infectious skin diseases. They are usually caused by the $\beta$-hemolytic group of Streptococcus, and less frequently by other bacteria. The objective of the study was to assess the factors affecting the length of stay of patients admitted to hospital with erysipelas or bacterial cellulitis.

Methods: The study was based on the retrospective analysis of medical records of patients diagnosed with erysipelas or bacterial cellulitis. Selected clinical features of the disease, the results of additional tests, the treatment used, and the time of hospitalization were analyzed. Among an initial group of 78 pre-identified patients, 59 subjects aged from 32 to 89 years were included in the final analysis. The time spent in the hospital and the number of antibiotics necessary to cure the patient were chosen as the parameters of treatment efficacy. Results: The average duration of stay in a hospital was $7.0 \pm 2.9$ days and was slightly longer for women than for men. Patients with chills on

Enhanced Digital Features To view enhanced digital features for this article go to https://doi.org/10.6084/ m9.figshare.7380668.

E. Kosior · A. Reich ( $\square)$

Department of Dermatology, University of Rzeszow, Rzeszow, Poland

e-mail: adi_medicalis@go2.pl admission, with coexisting chronic venous insufficiency of the lower limbs, and with anemia were hospitalized for a significantly longer period than those without these conditions. A combination therapeutic regimen of amoxicillin + clavulanic acid was the most commonly used treatment option, and this therapy was linked with shortest duration of stay in the hospital; the length of hospital stay was significantly longer for those patients receiving cephalosporins or clindamycin as treatment. The combination therapy of amoxicillin + clavulanic acid as treatment option was also least often associated with the need to use other antibacterial agents.

Conclusions: Based on our evaluation of 59 subjects with either erysipelas or bacterial cellulitis, combination therapy with amoxicillin + clavulanic acid appears to be linked with the shortest stay in the hospital. We suggest that this combination therapy should be considered as a first-line treatment for patients hospitalized due to erysipelas or bacterial cellulitis, if other factors did not preclude the use of this therapy.

Keywords: Bacterial infection; Prognosis; Skin; Treatment

\section{INTRODUCTION}

Erysipelas and bacterial cellulitis are two of the most common infectious skin diseases. They 
have the potential to cause significant morbidity, especially in patients who are burdened with internal diseases $[1,2]$. Diagnosis is usually made on the basis of the total clinical picture and abnormal laboratory test results. The typical clinical features of erysipelas include an inflammatory reaction limited to the dermis and lymph vessels with well-demarcated erythema, and the symptoms include fever, chills, nausea, and pain in the affected area [3]. The diagnosis of erysipelas cannot always be clearly separated from that of cellulitis, with the latter referring to inflammation of the deeper layers of the dermis and subcutaneous tissue [4]. Pathogens that play a major role in the etiology of erysipelas and cellulitis in adults are the $\beta$-hemolytic streptococci (especially Streptococcus pyogenes) and Staphylococcus aureus, although in rare other pathogenic bacteria have been, including Haemophilus influenzae, Klebsiella pneumoniae, Streptococcus pneumoniae, Yersinia enterocolitica, among others [5, 6]. Both diseases are the cause of urgent admissions to hospital wards, mainly due to the risk of severe complications, including sepsis. Such hospitalizations generate significant costs and are a significant financial burden for the health care system. Therefore, the decision on the type of antibiotic therapy used is extremely important because it has a significant impact on the course and duration of hospitalization and the global effectiveness of therapy.

The aim of the study reported here was to assess the factors affecting the duration of stay of patients admitted to hospital due to erysipelas or bacterial cellulitis.

\section{METHODS}

\section{Study Design}

The study was based on a retrospective analysis of clinical data of patients referred to hospital due to erysipelas or bacterial cellulitis and subsequently admitted to the Department of Dermatology, University of Rzeszow, between January 2016 and April 2018. Patients potentially eligible for inclusion in the study were pre-identified by searching the electronic database of the hospital to identify patients admitted to the hospital during the study period with suspected erysipelas or bacterial cellulitis, using the International Classification of Diseases, tenth revision (ICD-10) codes A46 (erysipelas), L03.0-L03.9 (cellulitis), and L08.0L08.9 (other local infection of the skin and subcutaneous tissue). A total of 78 patients were identified, among whom 59 were assessed as eligible to be included in the final analysis based on an evaluation of the medical documentation, including but not limited to data on the physical examination, microbiological examination, laboratory tests, and imaging studies. The remaining patients were excluded because the infectious background of the skin disease was not confirmed during the hospitalization period; these patients were most often diagnosed with and treated for exacerbation of chronic venous insufficiency of lower legs with stasis dermatitis.

The study was based on a structured questionnaire, which included such clinical features of the disease as location of skin lesions, clinical subtype of the disease, episode of the disease, clinical symptoms, and accompanying diseases, as well as the results of additional tests, such as presence of leukocytosis, increased erythrocyte sedimentation rate (ESR), and the serum C-reactive protein (CRP) level.

A number of parameters were a priori considered to be a determinant of the effectiveness of therapy; these were the length of stay in the hospital (longer duration of stay was considered to indicate inferior effectiveness of therapy), the number of antibiotics necessary to cure the patient, and the discharge mode from the department (transferring the patient to another ward instead of home was considered as a treatment failure). However, as only three of the 59 patients were transferred to another department, we considered this number too small to perform a reliable analysis and, therefore, this parameter was not taken into account in the final analysis of the results.

All procedures performed in studies involving human participants were in accordance with the institutional research committee and with the 1964 Helsinki Declaration and its later amendments or comparable ethical standards. 
Informed consent was obtained from all individual participants included in the study.

\section{Patients}

The study group included 59 patients aged from 32 to 89 (mean age $58.5 \pm 15.7$ ) years, of whom $34(57.6 \%)$ were women and $25(42.4 \%)$ men (ratio 1.36:1). Detailed characteristics of the analyzed population are presented in Table 1.

\section{Statistical Analysis}

The results of our evaluation were subjected to statistical analysis using the software package Statistica version 12.0 (StatSoft Polska Sp. z o.o., Krakow, Poland). Frequencies, minimum and maximum values, means \pm standard deviations (SD) were determined. While comparing quantitative data, we verified possible differences between the compared groups using Student's $t$ test for independent samples (for two groups) and analysis of variance when more than two groups were compared. For qualitative variables, the $\chi^{2}$-test with the Yates correction was used. Statistical analysis was carried out at the confidence level $\alpha=0.05$. Results for which the likelihood of making the first type of error by rejection of the null hypothesis, which was true, were less than 0.05 , were considered to be significant.

\section{RESULTS}

\section{Duration of Hospitalization}

The mean length of stay in the hospital ward was $7.0 \pm 2.9( \pm \mathrm{SD})$ days and was slightly longer for women (7.6 \pm 3.4 days) than for men $(6.5 \pm 2.0$ days; $p=0.25)$. Although differences in length of hospital stay did not reach statistical significance in the assessment of the impact of disease location $(p=0.06)$ (Table 2$)$, the mean length of hospital stay was significantly longer in patients with lesions on the lower limbs than in all other patients taken together $(7.5 \pm 3.0 \mathrm{vs}$. $5.1 \pm 1.3$ days; $p<0.01)$. In addition, patients with chills on admission stayed in the hospital
Table 1 Patient characteristics

Patient characteristics

Number of patients

(\%)

Gender

Males

$25(42.4)$

Females

$34(57.6)$

Disease localization

Face

$10(16.9)$

Trunk

$1(1.7)$

Upper extremities

$2(3.4)$

Lower extremities

46 (78.0)

Clinical subtype

Erythematous

Bullous

Hemorrhagic

$6(10.2)$

Disease episode

First

$43(72.9)$

Subsequent

$16(27.1)$

General symptoms

Fever $\left(>37.5^{\circ} \mathrm{C}\right)$

$39(66.1)$

Chills

Lymphadenopathy

8 (13.6)

Concomitant disorders

$\begin{array}{lc}\text { Arterial hypertension } & 26(44.1) \\ \text { Chronic venous insufficiency of } & 13(22.0) \\ \text { lower legs } & \\ \text { Diabetes } & 8(13.6) \\ \text { Anemia } & 8(13.6) \\ \text { Heart insufficiency } & 6(10.2) \\ \text { Malignancy } & 5(8.5) \\ \text { Hematologic disorder } & 5(8.5) \\ \text { Post-lymphadenectomy status } & 5(8.5) \\ \text { Chronic renal disease } & 3(5.1) \\ \text { Others } & 33(55.9)\end{array}$


Table 1 continued

\begin{tabular}{ll}
\hline Patient characteristics & $\begin{array}{l}\text { Number of patients } \\
(\%)\end{array}$ \\
\hline Laboratory examinations & \\
Elevated CRP & $56(94.9)$ \\
Elevated ESR & $49(83.1)$ \\
Leukocytosis & $11(18.6)$
\end{tabular}

CRP C-reactive protein, ESR erythrocyte sedimentation rate

significantly longer than those without admitted without chills $(8.6 \pm 4.3$ vs. $6.6 \pm 2.4$ days, respectively; $p<0.05)$. Chronic venous insufficiency of lower legs $(p=0.01)$ and anemia $(p=0.03)$ were also associated with prolonged hospitalization (Table 2). The clinical subtype of erysipelas/bacterial cellulitis, disease episode, and initial abnormal laboratory test results did not significantly influence the length of the patient's stay in the hospital (Table 2). Upon admission, $56(94.9 \%)$ patients had an elevated serum CRP level (mean $8.7 \pm 8.6 \mathrm{mg} / \mathrm{dl}$, range $1.1-36.2 \mathrm{mg} / \mathrm{dl}$; normal $<1.0 \mathrm{mg} / \mathrm{dl}$ ) and 49 $(83.1 \%)$ patients had an increased ESR (mean $49.9 \pm 28.8 \mathrm{~mm} / \mathrm{h}$, range $13-132 \mathrm{~mm} / \mathrm{h}$ ), while only $11(18.6 \%)$ had leukocytosis (mean $14.2 \pm 3.1 \times 10^{3}$ cells $/ \mu l$, range 10.2-18.7 $\times 10^{3}$ cells $/ \mu \mathrm{l})$. Multivariate regression analysis showed that the location of the disease on the lower limbs $(b=2.1, p=0.02)$ and the presence of chills $(b=1.9, p=0.03)$ were independent parameters with the potential to prolong a patient's stay in hospital.

\section{Antibacterial Treatment}

Regarding antibiotics, treatment was most often initiated with the combination of amoxicillin + clavulanic acid $(n=31)$, followed in decreasing frequency by initial treatment with clindamycin $(n=14)$ and cephalosporin $(n=14)$. The shortest hospitalization period was observed for patients treated with the combination amoxicillin + clavulanic acid, followed in decreasing frequency by treatment with cephalosporin and clindamycin $(p<0.05)$
Table 2 Comparison of hospitalization duration in different patient groups

\begin{tabular}{ll}
\hline Patient characteristics & $\begin{array}{l}\text { Duration of } \\
\text { hospitalization } \\
\text { (days) }\end{array}$
\end{tabular}

Disease localization

Face

$5.1 \pm 1.1$

0.06

Trunk

$5.0 \pm 0.0$

Upper extremities

$5.0 \pm 2.8$

Lower extremities

$7.5 \pm 3.0$

Clinical subtype

Erythematous

$7.1 \pm 2.8$

0.77

Bullous

$7.3 \pm 3.9$

Hemorrhagic

$7.2 \pm 4.2$

Disease episode

First

$7.2 \pm 3.2$

0.44

Subsequent

$6.5 \pm 2.1$

General symptoms

Fever $\left(>37.5^{\circ} \mathrm{C}\right)$

$7.1 \pm 2.9$

0.60

No fever

$6.7 \pm 3.1$

Chills

$8.6 \pm 4.3$

No chills

$6.6 \pm 2.4$

Lymphadenopathy

$6.4 \pm 4.8$

No lymphadenopathy

$7.1 \pm 2.5$

Concomitant disorders

Arterial hypertension

$7.6 \pm 3.2$

0.17

Chronic venous

$8.8 \pm 3.8$

0.01

insufficiency of lower

legs

Diabetes

$6.2 \pm 1.9$

0.45

Anemia

$9.0 \pm 3.0$

0.03

Heart insufficiency

$7.7 \pm 2.0$

0.55

Malignancy

$5.4 \pm 1.3$

0.21

Hematologic disorder

$9.0 \pm 4.3$

0.11

Post-lymphadenectomy

$6.4 \pm 0.9$

0.64

status 
Table 2 continued

\begin{tabular}{lll}
\hline Patient characteristics & $\begin{array}{l}\text { Duration of } \\
\text { hospitalization } \\
\text { (days) }\end{array}$ & $\boldsymbol{p}$ \\
\hline Chronic renal disease & $6.3 \pm 0.6$ & 0.69 \\
Others & $7.7 \pm 3.1$ & - \\
Laboratory examinations & $6.9 \pm 2.8$ & 0.31 \\
Elevated CRP & $7.0 \pm 3.1$ & 0.88 \\
Elevated ESR & $6.4 \pm 2.1$ & 0.51 \\
Leukocytosis &
\end{tabular}

Data in table on duration of hospitalization are presented as the mean \pm standard deviation $(\mathrm{SD})$

(Table 3). Patients treated with amoxicillin + clavulanic acid were also the least likely to require the prescription of an additional antibiotic to treat the skin infection, while those treated with clindamycin were prescribed other antibiotics significantly more often, mostly metronidazole.

A detailed analysis of the impact of the clinical parameters on the number of antibiotics used in a given patient is provided in Table 4 . None of the analyzed parameters significantly influenced the need to use a larger number of antibiotics, with the exception of sex-the average number of antibiotics used were higher for women (mean $1.5 \pm 0.6$ antibiotics) than for men (mean $1.2 \pm 0.4$ antibiotics; $p=0.03$ ). However, we observed that compared to all other patients, patients treated initially with amoxicillin + clavulanic acid had a significantly lower frequency of bullous lesions $(3.2 \%$ vs.
$21.4 \% ; p<0.05)$ and often suffered less from concomitant hematologic disorders $(0 \%$ vs. $17.9 \% ; p=0.02)$. In comparison, patients treated initially with clindamycin had higher ESR on admission than other patients $(67.0 \pm 37.3$ vs. $45.5 \pm 24.9 \mathrm{~mm} / \mathrm{h} ; p=0.03$ ) and more frequently suffered concomitantly from hematologic conditions $(28.6 \%$ vs. $2.2 \% ; p=0.01)$.

\section{DISCUSSION}

Erysipelas and cellulitis are two skin diseases that constitute a significant clinical problem and are of interest to physicians of various specialties. Each year, new study results and newly proposed guidelines lead to new proposals on the optimal management of both of these clinical entities. However, the problem of choosing the optimal treatment remains actual, primarily because the antibiotic susceptibility of the most common pathogens causing these skin diseases differs locally and may change over time. Despite the significant morbidity associated with erysipelas and bacterial cellulitis, data on the efficacy of antibiotics used in the therapy of these diseases are limited [7]. Kilburn et al. [8] in the Cochrane meta-analysis evaluated 25 studies of bacterial skin infection but were unable to clearly determine the final conclusions regarding optimal antimicrobial cellulitis therapy.

Based on the results obtained in our study, we suggest that the treatment of bacterial skin infection with the combination therapy of amoxicillin + clavulanic acid should result in the fastest clinical improvement, thus reducing

Table 3 Antibacterial treatment and duration of the hospitalization

\begin{tabular}{lllll}
\hline $\begin{array}{l}\text { Antibacterial } \\
\text { treatment }\end{array}$ & $\begin{array}{l}\text { Number of } \\
\text { patients }\end{array}$ & $\begin{array}{l}\text { Mean duration of } \\
\text { hospitalization (days) }\end{array}$ & $\boldsymbol{p}$ & $\begin{array}{l}\text { Number of patients } \\
\text { requiring additional } \\
\text { antibiotics }\end{array}$ \\
\hline $\begin{array}{l}\text { Amoxicillin }+ \\
\text { clavulanic acid }\end{array}$ & 31 & $6.5 \pm 2.3$ & $<0.05$ & $7(22.6 \%)$ \\
$\begin{array}{l}\text { Cephalosporins } \\
\text { Clindamycin }\end{array}$ & 14 & $7.2 \pm 2.7$ & $7(50.0 \%)$ \\
\hline
\end{tabular}

Data on mean duration of hospitalization are presented as the number $\pm \mathrm{SD}$ 
Table 4 Comparison of mean number of various antibiotics used in patient subgroups

\begin{tabular}{|c|c|c|}
\hline Patient characteristics & $\begin{array}{l}\text { Number of } \\
\text { antibiotics used }\end{array}$ & $p$ \\
\hline \multicolumn{3}{|l|}{ Disease localization } \\
\hline Face & $1.0 \pm 0.0$ & 0.06 \\
\hline Trunk & $2.0 \pm 0.0$ & \\
\hline Upper extremities & $2.0 \pm 0.0$ & \\
\hline Lower extremities & $1.4 \pm 0.5$ & \\
\hline \multicolumn{3}{|l|}{ Clinical subtype } \\
\hline Erythematous & $1.4 \pm 0.5$ & 0.77 \\
\hline Bullous & $1.6 \pm 0.5$ & \\
\hline Hemorrhagic & $1.3 \pm 0.5$ & \\
\hline \multicolumn{3}{|l|}{ Disease episode } \\
\hline First & $1.3 \pm 0.5$ & 0.56 \\
\hline Subsequent & $1.4 \pm 0.5$ & \\
\hline \multicolumn{3}{|l|}{ General symptoms } \\
\hline Fever $\left(>37.5^{\circ} \mathrm{C}\right)$ & $1.4 \pm 0.5$ & 0.69 \\
\hline No fever & $1.3 \pm 0.6$ & \\
\hline Chills & $1.4 \pm 0.7$ & 0.73 \\
\hline No chills & $1.4 \pm 0.5$ & \\
\hline Lymphadenopathy & $1.2 \pm 0.7$ & 0.33 \\
\hline No lymphadenopathy & $1.4 \pm 0.5$ & \\
\hline \multicolumn{3}{|l|}{ Concomitant disorders } \\
\hline Arterial hypertension & $1.5 \pm 0.6$ & 0.39 \\
\hline $\begin{array}{l}\text { Chronic venous } \\
\text { insufficiency of lower legs }\end{array}$ & $1.5 \pm 0.7$ & 0.39 \\
\hline Diabetes & $1.1 \pm 0.3$ & 0.23 \\
\hline Anemia & $1.5 \pm 0.5$ & 0.49 \\
\hline Heart insufficiency & $1.5 \pm 0.5$ & 0.56 \\
\hline Malignancy & $1.0 \pm 0.0$ & 0.16 \\
\hline Hematologic disorder & $1.8 \pm 0.4$ & 0.09 \\
\hline $\begin{array}{l}\text { Post-lymphadenectomy } \\
\text { status }\end{array}$ & $1.2 \pm 0.4$ & 0.53 \\
\hline Chronic renal disease & $1.3 \pm 0.6$ & 0.94 \\
\hline Others & $1.4 \pm 0.6$ & - \\
\hline
\end{tabular}

Table 4 continued

\begin{tabular}{lll}
\hline Patient characteristics & $\begin{array}{l}\text { Number of } \\
\text { antibiotics used }\end{array}$ & $\boldsymbol{p}$ \\
\hline Laboratory examinations & & \\
Elevated CRP & $1.4 \pm 0.5$ & 0.28 \\
Elevated ESR & $1.4 \pm 0.3$ & 0.72 \\
Leukocytosis & $1.4 \pm 0.5$ & 0.57 \\
\hline
\end{tabular}

Data on number of antibiotics used are presented as the mean $\pm \mathrm{SD}$

the length of the hospital stay and subsequently reducing the costs of treatment of patients with erysipelas or bacterial cellulitis. We noted that the fast improvement in the amoxicillin/clavulanic acid-treated patient group was rarely associated with the need to use other antibacterial agents, either concomitantly or sequentially, which may further support the use of these drugs as the first-line treatment. However, our observations should be taken with caution due to a retrospective nature of the analysis, which may have been influenced by a number of confounding factors that were not adequately addressed in the study (e.g., personal preferences of physicians while choosing particular treatment option, concomitant diseases, severity of the infection, etc.).

In a retrospective study conducted by Bishare et al. [9], patients treated with penicillin required a shorter hospitalization. In the same study, these researchers did not find significant benefits from the use of antibiotics other than penicillin. In the analysis of Krasagakis et al. [10], the most commonly used antibiotic was intravenously administered penicillin G. These authors found that the group receiving this antibiotic by this route had the shortest mean duration of fever after initiation of treatment than all other patient groups. In turn, a study conducted by Perelló-Alzamora et al. [11] demonstrated that the majority of patients showed improvement or were cured with amoxicillin in combination with clavulanic acid, with no serious side effects of this therapy. For patients who could not tolerate this combination of antibiotics, an alternative form of 
treatment, namely, clindamycin or quinolones, was used with a satisfactory effect.

At the present time there is no unambiguous consensus regarding empiric therapy of erysipelas and bacterial cellulitis. The UK guidelines $[12,13]$ still recommend amoxicillin or flucloxacillin as the first-line treatment in most cases of bacterial dermatitis and subcutaneous tissue infection caused by $\beta$-hemolytic streptococci, $S$. aureus, or when the pathogen has not been identified. In the case of penicillin allergy, macrolide antibiotics or clindamycin are recommended as a suitable alternative.

We also found coexisting chronic venous insufficiency of the lower limbs was a significant factor in prolonging the duration of hospitalization. This disease causes not only stasis in the venous circulation, but also, in some cases, may lead to lymphatic edema, which has been considered by many researchers to be one of the main factors predisposing a person to development of erysipelas and bacterial cellulitis as well as to its recurrence. Dupuy et al. [14] in their study found that lymphedema played the most important role in the pathomechanism of bacterial skin infection. Pavlotsky et al. [15] also came to a similar conclusion, emphasizing that the factors contributing to the recurrence of the disease are, in particular, venous insufficiency, lymphoedema, as well as coexisting tinea pedis. Data on the coexistence of anemia in patients hospitalized for bacterial cellulitis and its effect on the course of the disease are less evident. In our patients, clinically significant anemia, defined as a hemoglobin concentration of $<10 \mathrm{~g} / \mathrm{dl}$, was found to be a factor that significantly increased the length of stay in the ward. One possible explanation for this is that patients with anemia usually are in poorer general condition compared to the other subjects. In addition, a lower hemoglobin level ensures a lower oxygen supply and thus might increase ischemia provoked by the cutaneous infection, leading to increased tissue damage.

It must be emphasized that our results have a number of limitations that need to be taken into account when interpreting the results. First, the study was conducted on a relatively small number of patients from one center; ideally the study should be repeated in other hospitals. Another important limitation is the retrospective nature of the study, which cannot fully elucidate the reasons for choosing a particular therapy option over another; as a result, many confounding factors cannot be excluded from the study. The lack of randomized allocation to particular treatment option may further have influenced of the results, as the analyzed groups may differ significantly in terms of the severity of the disease as well as the severity of concomitant diseases. We suggest, however, that the obtained results can be of practical importance as they might help to optimize the recommendations for the treatment of erysipelas and bacterial cellulitis by explicitly indicating a combination of amoxicillin + clavulanic acid as likely being a more effective form of antibiotic therapy compared to other drugs. Undoubtedly, our observations need confirmation in a prospective study on a larger group of patients, which should allow verification and possible confirmation of the conclusions made in the current study.

\section{CONCLUSIONS}

Treatment with the combination of amoxicillin + clavulanic acid appears to be linked with the shortest stay in the hospital in patients with erysipelas or bacterial cellulitis. Based on the results of our preliminary study, we suggest that these drugs should probably be considered as a first-line treatment for patients suffering from these conditions.

\section{ACKNOWLEDGEMENTS}

Funding. This is an investigator-initiated study and no funding or sponsorship was received for this study or publication of this article.

Authorship. All named authors meet the International Committee of Medical Journal Editors (ICMJE) criteria for authorship for this article, take responsibility for the integrity of 
the work as a whole, and have given their approval for this version to be published.

Disclosures. Ewelina Kosior declares that she has no disclosures regarding this manuscript. Adam Reich has worked as a Consultant or Speaker for AbbVie, Alfasigma, Astellas, Berlin-Chemie/Menarini, Bioderma, Celgene, Chema Elektromet, Eli Lilly, Galderma, Janssen, Leo Pharma, Medac, Menlo Therapeutics, Novartis, Pierre-Fabre, and Trevi.

Compliance with Ethics Guidelines. All procedures performed in studies involving human participants were in accordance with the institutional research committee and with the 1964 Helsinki Declaration and its later amendments or comparable ethical standards. Informed consent was obtained from all individual participants included in the study.

Data Availability. The datasets during and/ or analyzed during the current study are available from the corresponding author on reasonable request.

Open Access. This article is distributed under the terms of the Creative Commons Attribution-NonCommercial 4.0 International License (http://creativecommons.org/licenses/ by-nc/4.0/), which permits any noncommercial use, distribution, and reproduction in any medium, provided you give appropriate credit to the original author(s) and the source, provide a link to the Creative Commons license, and indicate if changes were made.

\section{REFERENCES}

1. Goettsch WG, Bouwes Bavinck JN, Herings RMC. Burden of illness of bacterial cellulitis and erysipelas of the leg in The Netherlands. J Eur Acad Dermatol Venereol. 2006;20:834-9.

2. Inghammar M, Rasmussen M, Linder A. Recurrent erysipelas-risk factors and clinical presentation. BMC Infect Dis. 2014;14:270.
3. Bonnetblanc J-M, Bédane C. Erysipelas: recognition and management. Am J Clin Dermatol. 2003;4:157-63.

4. Stevens DL, Bisno AL, Chambers HF, et al. Practice guidelines for the diagnosis and management of skin and soft tissue infections: 2014 update by the Infectious Diseases Society of America. Clin Infect Dis. 2014;59:e10-52.

5. Morris AD. Cellulitis and erysipelas. BMJ Clin Evid. 2008;2008:1708.

6. Denis F, Martin C, Ploy MC. Erysipelas: microbiological and pathogenic data. Ann Dermatol Venereol. 2001;128:317-25.

7. Maxwell-Scott H, Kandil H. Diagnosis and management of cellulitis and erysipelas. Br J Hosp Med (Lond). 2015;76:C114-7.

8. Kilburn SA, Featherstone P, Higgins B, Brindle R. Interventions for cellulitis and erysipelas. Cochrane Database Syst Rev. 2010;6:CD004299.

9. Bishara J, Golan-Cohen A, Robenshtok E, Leibovici L, Pitlik S. Antibiotic use in patients with erysipelas: a retrospective study. Isr Med Assoc J. 2001;3:722-4.

10. Krasagakis K, Valachis A, Maniatakis P, Krüger-Krasagakis S, Samonis G, Tosca AD. Analysis of epidemiology, clinical features and management of erysipelas. Int J Dermatol. 2010;49:1012-7.

11. Perelló-Alzamora M-R, Santos-Duran J-C, SánchezBarba M, Cañueto J, Marcos M, Unamuno P. Clinical and epidemiological characteristics of adult patients hospitalized for erysipelas and cellulitis. Eur J Clin Microbiol Infect Dis. 2012;31:2147-52.

12. Clinical Resource Efficiency Support Team. Guidelines on the management of cellulitis in adults. http://www.acutemed.co.uk/docs/Cellulitis\%20guide lines,\%20CREST,\%2005.pdf. Accessed 12 Oct 2018.

13. Phoenix G, Das S, Joshi M. Diagnosis and management of cellulitis. Br Med J. 2012;345:e4955.

14. Dupuy A, Benchikhi H, Roujeau J, et al. Risk factors for erysipelas of the leg (cellulitis): case control study. Br Med J. 1999;318:1591-4.

15. Pavlotsky F, Amrani S, Trau H. Recurrent erysipelas: risk factors. J Dtsch Dermatol Ges. 2004;2:89-95. 